\title{
¿Quién no tiene sueños?: un relato entre el desarraigo y la libertad
}

\section{Who has no dreams?: a story between uprooting and freedom}

DOI: https://doi.org/10.29166/tyc.v1i19.2068

\section{Dachel Annelys García Matos}

Estudiante de séptimo semestre de la Facultad de Comunicación Social de la Universidad Central del Ecuador. Entre sus principales líneas de investigación están los lenguajes y los discursos de la información y la comunicación; recepción, consumo e interacción en los productos comunicacionales; información, comunicación y cultura. Actualmente prepara una tesis acerca de la dinámica comunicacional en el contexto de la inmigración internacional en el barrio La Florida en Quito, Ecuador.

Correo: dagarciam@uce.edu.ec

\section{Mariela Pozo Chávez}

Estudiante de séptimo semestre de la Facultad de Comunicación Social de la Universidad Central del Ecuador. Entre sus principales líneas de investigación se encuentran las diversas formas del consumo cultural y la construcción de significados. Actualmente prepara una tesis acerca de la representación del periodista en películas del contexto nacional.

Correo:mpozoc@uce.edu.ec

\section{Resumen}

El testimonio, camino recurrente del periodismo para acudir a la memoria, presenta hasta la actualidad muchas posibilidades de uso. Este artículo narra, en la primera parte, el testimonio de un migrante hacia Ecuador, y da cuenta del amplio significado y magnitud de las movilizaciones humanas. En la segunda parte, se desarrolla una reflexión teórica acerca de la importancia del testimonio dentro del denominado nuevo periodismo. Se analizan además los límites y posibilidades del testimonio como herramienta para comprender la propia historia nacional, para vivir y reconocer lo que es ahora el Ecuador.

Palabras clave: clave: testimonio, migración, memoria, narrativa, periodismo.

\section{Abstract}

The testimony, recurrent journalism path to appeal the memory, it presents so far a lot of usage possibilities. This article narrates, in its first part, a migrant's testimony about Ecuador, and he gives assurance about the meaning and magnitude of human mobilization. In the second part, a theoretical reflection about the value of the testimony inside the one which is called new journalism. Furthermore, it is checked the boundaries and possibilities of the testimony as a tool to understand the national history itself, to live and recognize what it is Ecuador nowadays.

Keywords: testimony, migration, memory, narrative, journalism. 


\section{1}

\section{Cuando el único camino es la fuga}

Desde las primeras formas de organización humanas, nuestros antepasados se desplazaban por todas las regiones habitables del mundo. Buscaron lugares donde sobrevivir y asentarse. Actualmente, los procesos migratorios no han parado. Los motivos pueden ser diferentes, algunos políticos, otros económicos, pero siempre estamos en movimiento.

La migración, sin duda, es un fenómeno que ha tenido grandes repercusiones a nivel cultural, social, económico y político. En los últimos años, Ecuador se ha convertido en un país receptor, en su gran mayoría, de migrantes fronterizos. En el 2018, más de 2 millones de persona ingresaron al país, de las cuales solo el $8.7 \%$ indicó en sus registros de entrada que se quedarían permanentemente en el país (INEC, 2019). Sin embargo, Refugees International (2019) publicó una investigación en la que se afirma que los migrantes, especialmente provenientes de Venezuela, llegan en calidad de turistas para luego quedarse o seguir hacia el sur.

Pero más allá de los datos, el estudio del tema migratorio contiene historias con rostros propios, que en sus particularidades no son un dato más. Las memorias y vivencias de los migrantes necesitan ser contadas, quizá así se dé cuenta del amplio significado y magnitud de las movilizaciones humanas. Es necesario conocer los testimonios de los otros, los llamados extranjeros, para narrar la propia historia nacional, para vivir y reconocer lo que es ahora el Ecuador.

Félix Alberto García Pérez nació en Cuba, estudió medicina en la Universidad de Granma y se especializó en ginecobs- tetricia. Se casó a los 20 años con Raquel Rubí Matos Zamora, su compañera de estudios y amiga. Años más tarde tuvo dos hijas. A los 30 años se mudó desde Granma, su ciudad natal, a La Habana, y actualmente vive en Quito, Ecuador. Tiene 50 años y es uno de los innumerables ejemplos de aquello que viven los migrantes para lograr sus sueños.

Si preguntan sobre su carácter se puede decir que tiene un gran sentido del humor, aunque esto no se puede apreciar a simple vista. Si solo nos quedáramos con el contacto inicial, pensaríamos que es una persona muy seria y desconfiada. Pero en este caso la primera impresión no es la que contará. Es alto, tiene la piel muy blanca, y poco pelo. Habla fuerte y rápido, al son del acento cubano. Dice que suele adaptarse rápidamente, quizá por los cambios drásticos que ha vivido a lo largo de su vida.

Según cifras publicadas por la Organización para la Cooperación y el Desarrollo Económicos (2013) cerca de un millón y medio de cubanos han emigrado de la isla. En Ecuador, según cifras del Ministerio del Interior (citado en Vaca, 2017), 79173 cubanos han arribado después de que el Estado exigiera visa para su ingreso. Algunos se quedarán por poco tiempo y luego seguirán su camino hacia el norte. Otros permanecerán en el país. Seguimos en movimiento. La historia de los seres humanos es una historia de migraciones.

- La verdad es que no me siento del todo cómodo recordando aquel momento - dice Félix fijando sus ojos verdes y llorosos sobre sus manos, mientras recuerda por qué salió de Cuba. Se sienta frente a la mesa de su sala. Ahí estamos nosotras, dispuestas a escucharlo. 
- No se preocupe, en el momento que desee podemos parar, imaginamos que debe ser difícil para usted - intentamos ponernos en su lugar.

- Entonces solo perdonen si me emociono - dice antes de comenzar a contarnos cómo salió de Cuba. Habla del pasado como quien encuentra una carta que no vale la pena volver a leer.

De inmediato, Félix comienza a relatar cómo fue el largo proceso:

- La situación que vivía en Cuba, sin ser una situación extrema era bastante difícil desde el punto de vista económico. Lo peor de todo era la frustración que vivía. Uno tiene una profesión, un trabajo, sin embargo, las cosas básicas que necesitamos, no las teníamos. Ese fue el principal detonante para que decidiera emigrar ¿Quién no tiene sueños? Yo no podía realizar los míos y lógicamente la economía iba asfixiando. Aunque también soy de los que piensa que detrás de una situación económica difícil siempre hay políticos que la provocan, gente que no sabe manejar un país y lo lleva al fracaso.

\section{Con mi salario era imposible ahorrar dinero}

Muchos viven a espaldas de esta realidad migratoria. Durante su campaña política, Jair Bolsonaro (2018) increpaba, a voz en cuello: "No hacen nada. Más de mil millones de dólares al año estamos gastando en ellos", al referirse sobre todo a los ciudadanos con ascendencia africana. Al norte, Trump se preguntaba por qué Estados Unidos tenía tanta gente de países que son "agujeros de mierda" viviendo ahí (EFE, 2018). Hablar de migración es un tema álgido en las agendas presidenciales de todo el mundo. Un tema que atraviesa muchos aspectos, uno de los principales, el económico.

El salario básico en Cuba es de 16 dólares (Redacción Cubadebate, 2019). El costo de trámites del pasaporte, visado y pasajes hacia Ecuador bordea los 1.200 dólares, lo que equivale a 75 sueldos básicos. Más de seis años de ahorro, sin contar que con el monto mensual ganado se debe comprar comida, pagar transporte, entre otros, a pesar de los subsidios. La salud y la educación son de acceso gratuito en Cuba, y sus ciudadanos reciben algunos alimentos del Estado mediante la "libreta de abastecimiento". Pero esa cartilla, que hace décadas llegó a cubrir gran parte de las necesidades -incluso la ropa interior, los zapatos y los juguetes infantiles-, se ha reducido en cantidad y tipo de productos subsidiados.

Preguntamos cómo hizo Félix para juntar ese dinero, y después de un gran silencio, respondió:

El financiamiento fue bastante difícil porque con mi salario era imposible ahorrar dinero. Para salir del país tuve que recurrir a múltiples cosas. Durante mi vida profesional conocí personas que me ayudaron económicamente y que me obsequiaron objetos de cierto valor en agradecimiento por mi labor como médico obstetra. Todo eso tuve que venderlo, ropa, joyas, algunos artefactos. Yo no tenía casa propia, por eso, ni pensar en conseguir dinero alquilándola. El resto lo fui sumando de varias cosas que se hicieron, algunas incluso estaban al margen de la legalidad. En la isla existen "negociantes" que se dedican al tráfico de personas.

En Cuba hay una cantidad significativa de gente que quiere salir del país y constantemente busca alternativas. Yo, 
por mi profesión, conocía a muchas personas, entre ellas al esposo de una paciente, quien a su vez conocía a un abogado boliviano que se dedicaba a sacar personas a través de cartas de invitación a su país de origen. Julián (nombre que utilizaremos para proteger la identidad de este abogado) proponía a los médicos una vía supuestamente fácil: ir a eventos científicos, tener trabajo y una serie de promesas falsas. Su único objetivo era enganchar a la gente para que se metieran a su negocio de migración. Pensó en mí porque creía que yo tenía cierta solvencia económica, lo cual era falso y me planteó la situación.

Tiempo después, conversando con un amigo que igualmente estaba desesperado por salir de Cuba, y entendiendo su situación, le comenté que conocía a una persona que le podría ayudar. Le dije de qué modo el abogado sacaba a los cubanos y así se hizo una cadena de tres o cuatro personas, hasta que llegó a oídos de otra persona que también se dedicaba al tráfico de personas desde Cuba. Los sacaba con ayuda de terceros hasta Estados Unidos. Resulta ser que él, que yo no sabía que se dedicaba a eso, también era conocido mío, yo había atendido a su esposa durante el embarazo y por ahí surgió la conexión.

Él me dijo que, si le presentaba al abogado del que les comentaba anteriormente, podían negociar para sacar personas que ya tenía previsto sacar, y de ahí, a manera de retribución por ponerlos en contacto, me pagaba el viaje.

Entonces, se puede decir que esa cadena de acontecimientos se generó por personas que yo conocía y que vieron en mí a alguien confiable, a quién se le podía contar esas cosas, porque, lógicamente, no a cualquiera se le da ese tipo

46 - Noviembre 2019 - Abril 2020 de detalles porque puede resultar en una intervención policial. Así que realmente son personas comunes y corrientes que entran a ese negocio ilegal. En Cuba la desesperación es grande y, una vez dentro de ese mundo ilícito, ven la posibilidad de tener ganancias relativamente fáciles.

Cada vez que puede, Félix menciona a su familia. El amor que siente por ellos es su motor principal, lo que lo movió a buscar los medios para su sustento, aunque eso implicara el enorme esfuerzo de salir de su país, para empezar una vida desde cero en otro lugar.

- Para mí lo más difícil - dice con la voz entrecortada - fue el hecho de dejar a mi familia. Realmente no fue mi decisión salir de Cuba sin ellos, sino que era imposible no hacerlo. Mi posibilidad de salir era remota, y logré financiamiento para mí por vías que no eran las legales. Imagínense ustedes, lograr financiamiento para mi esposa y mis hijas. Además, estaba la incertidumbre del futuro. Yo salí sin conocimiento de a dónde me dirigía y exponer a mi familia a eso era peor. Sabía que me tocaría duro, y con ellas sería mucho peor, entonces sería sufrir doblemente y no quería correr ese riesgo con mi familia.

\section{Aquel día, una pesadilla}

La gran mayoría de los países miembros de la ONU firmaron en diciembre del 2018, el primer acuerdo global para ayudar y proteger a los migrantes (CEPAL, 2018). Este convenio 
llamado, Pacto Mundial para la Migración Segura, Ordenada y Regular, se estructura con 23 objetivos. Entre los más relevantes está el de aumentar el apoyo a los mecanismos de prestación de asistencia monetaria para los migrantes y proteger la seguridad, la dignidad, así como los derechos humanos y las libertades fundamentales de todos los migrantes, sea cual sea su estatus migratorio, en todo momento.

Cuando Félix migró, este convenio no estaba ni siquiera planeado ¿Hubiera cambiado su situación? Es algo que nunca podremos saber. Él describe como una "pesadilla" aquel día en el que comenzó a construir su historia a distancia, cuando se despidió de su familia y el avión despegó rumbo a un destino que eligió casi a dedo. La recuerda así:

Ese lunes, 30 de septiembre de 2013, fue un día difícil, era como una pesadilla. Tuve que hacerme prácticamente invisible para que no vieran lo que estaba sintiendo. Realmente es bien difícil, traté de mostrar la menor cantidad de sentimientos posibles, pero por dentro estaba preocupado y dolido. Fue una mezcla de sentimientos que es indescriptible, hay que vivirlo para realmente poder sentirlo, porque no se puede explicar.

Imagínate dejar todo, tus amigos, tus padres, tus vecinos, tu comida, todo lo que te pertenece. $Y$ no porque quieras sino porque te toca. Dejar atrás mi familia, toda la vida que había forjado fue duro, muy duro realmente. Es una de las cosas de las que nunca he hablado y que no vale la pena recordar -logra pronunciar con la voz entrecortada y lágrimas en los ojos. Abandona la sala durante unos minutos acompañado por su esposa que intenta tranquilizarlo.

\section{Un viaje ilegal}

Regresa nuevamente a la sala, se sienta y continúa hablando, casi sin aire y todavía con los ojos rojos. No es fácil para él y no es menos complicado para quienes dejó atrás. Estar lejos de la patria, de casa, supone un acto de coraje, una tonelada de esfuerzo, un poco de desapego y un montón de ganas. Y continúa el relato:

Salí de Cuba rumbo a Bolivia, con una carta de invitación y una visa de turismo. Allí no conocía nada, ni si quiera tenía la más mínima idea de lo que iba a hacer. Llegué en horas de la madrugada y, como tenía visa, todo fue muy rápido. En esta misma odisea se involucró un compañero de trabajo y amigo, también profesional, que le pagó a ese traficante de personas para salir. Llegamos juntos con una idea más o menos vaga de qué queríamos hacer, ver si trabajábamos profesionalmente como médicos, si podíamos reunirnos con la familia lo antes posible, pero la idea de cómo lograrlo no era clara.

Nos comunicamos con un profesor de matemáticas, que incluso había sido profesor de mi hija menor, y que salió a Bolivia en ese mismo grupo de personas que migramos por la misma vía, que si mal no recuerdo fuimos alrededor de 10. Le llamamos desde una cabina telefónica, en el propio aeropuerto, y nos dijo que fuéramos al sitio donde él estaba. Se encontraba en una ciudad fronteriza con Brasil que se llama Cobija.

En este lugar estuvimos viviendo en un hotel malísimo, que incluso tenía rota la puerta y teníamos que entrar por la ventana. Él dormía en la cama y nosotros en el piso. Preguntando y preguntando nos dijeron que era bastante complicado poderse legalizar y decidimos continuar 
camino buscando otras opciones. Solicitamos una visa de entrada a Brasil, y nos la dieron. En ese momento ya habíamos planeado venir a Ecuador, porque mi acompañante tenía aquí al excuñado y padre de su sobrina. La situación de Ecuador en aquel momento permitía una fácil legalización y eso fue lo que nos motivó. La respuesta del país hacia la migración era mucho más favorable en comparación con otros países de la región. El presidente de entonces hablaba de la ciudadanía universal.

De ahí atravesamos Brasil y fuimos hasta Perú. A Perú entramos de manera ilegal, fue un tránsito bastante difícil, nos detuvo la policía en la entrada al país, tuvimos que pagar para que nos dejaran regresar a Brasil porque, de lo contrario, iríamos presos. Al día siguiente retornamos, tuvimos que incluso dejar la ropa en un hotel, porque teníamos que ir lo más ligeros posible de equipaje. Y así atravesamos Perú, arriesgándonos, hasta llegar a Ecuador, donde igualmente entramos sin ningún tipo de documentación, sin sellar el pasaporte, ni nada. Creo que la parte más difícil de la travesía fue esa de Perú, bien compleja, con muchos riesgos, con muchas cuestiones que nos pasaron, fue realmente difícil. Pero bueno, gracias a Dios pudimos llegar vivos y sanos y continuar nuestra vida en Ecuador.

\section{Primer día en Ecuador}

Visto como una solución o un agravante de la situación migratoria, el Pacto Mundial para la Migración Segura, Ordenada y Regular, tiene una característica particular. No es un tratado, ni es jurídicamente vinculante. Es decir, los países pueden o no cumplirlo. No es obligatorio,

48 - Noviembre 2019 - Abril 2020 depende de la disposición del gobierno de turno. Lo cierto es que muchos migrantes siguen aquí y allá. Yendo y viniendo en días, meses o años.

\section{Según recuerda Félix Alberto:}

Mi primer día en Ecuador fue común y corriente, no fue ni siquiera un día impactante. Fue desestresarse del viaje - nos comenta mirando a lo lejos, como si en su cabeza regresara a aquel 6 de octubre del 2013-. Recuerdo que llegamos en horas de la mañana, y lo primero que hicimos fue bañarnos. Hacía mucho tiempo que no nos bañábamos de manera tranquila. Comimos un plato de comida caliente y hecho en casa. Por lo demás, llegamos a casa de un conocido, también cubano. Le contamos la travesía y comenzamos a planificar el rumbo que tomaríamos. Al atardecer, este compatriota que nos recibió y que tenía una situación económica bastante solvente, nos invitó a conocer parte de la ciudad en su auto. Dormimos temprano, con bastante frío porque el cambio de temperatura se sentía. Ese fue el primer día, un día de rutina, nada significativo realmente.

Nos cuenta que en los primeros tiempos tuvo que ocuparse en labores diferentes a su profesión. Su lógica era la siguiente: llegar, conseguir trabajo, estabilizarse, lo cual podría demorar un año, y luego intentar retomar su profesión. Pero no fue nada fácil y así lo relata:

Yo recuerdo que, desde pequeño, dije que iba a ser médico, en parte por el reconocimiento social que tiene esta profesión a nivel internacional. En todos los países los médicos tienen gran prestigio, 
fundamentalmente porque velan por lo más importante para el ser humano que es la salud. El detonante para que me decidiera a ser médico fue ese principalmente, que me gusta ayudar a las personas.

Cuando llegué, no tenía dinero, ni los documentos para poder homologar mi título de profesional y no había sellado mi pasaporte, es decir, no tenía ningún documento de respaldo. Por eso tuve que comenzar a buscar empleo en lo que apareciera. Eso fue difícil porque en ocasiones no podía creer que tantos años de estudio no sirvieran para nada.

Algunas personas me recomendaron para que pudiera trabajar. En un primer momento trabajé en un almacén de cosméticos y tuve que aprender porque yo no tenía idea de la cantidad de productos que existían. Lo que hacía era preparar pedidos que hacían centros comerciales, tiendas pequeñas, clasificaba los productos en sus respectivos cartones para que fueran enviados a las personas que los compraban. Este era un trabajo eventual, cuando había carga de trabajo buscaban personas que colaboraran porque eran muchos los pedidos y poco el personal con el que contaban.

Después de esto trabajé en una pequeña fábrica en la que se hacían piezas de caucho, generalmente era en horarios nocturnos y en la madrugada. Estos fueron los dos trabajos que pude realizar inicialmente hasta que pude llegar a laborar como médico, pues me dieron la oportunidad de sustituir a un médico que había conseguido un nuevo empleo y no tenían quién de momento pudiera cubrir esa plaza. Fui por una jornada nada más a una empresa petrolera. Cuando comencé a trabajar, al parecer a los de Recursos Humanos de la empresa les gustó la forma en que trabajé, la responsabilidad, y me dieron la posibilidad de mantenerme ahí.

\section{Problemas}

Félix retoma la historia luego de beber un vaso de agua para contarnos que aquí está y sigue su lucha a pesar de las adversidades que pudo encontrar en todo este tiempo:

- Pasé muchísimos momentos difíciles por el hecho de que estuve un año indocumentado. Salía a la calle con el miedo de que me pidieran los documentos. Pasé momentos duros. Incluso hubo una ocasión en que, por esta misma cuestión de no tener los documentos de estancia en el país, me llevaron a una celda. Estuve casi 24 horas en una celda retenido, con un grupo de delincuentes comunes. Yo, por una cuestión migratoria, estaba mezclado con personas involucradas en el microtráfico de drogas, con ladrones, y otros que estaban por delitos informáticos. En mi caso estaba allí por tener un sello en el pasaporte que no correspondía a mi entrada legal al país, y se pensó que mi pasaporte era falso, lo que se demostró que no era así. A las 24 horas pude salir, pero fueron momentos bien difíciles esos de estar ahí en esa celda un día entero.

\section{Reencuentro}

Félix nos cuenta cómo fue el reencuentro con su esposa y unos meses después con sus hijas. Nos dice que las abrazó muy fuerte como intentando borrar en ese instante todo el tiempo que permanecieron separados: 
Una vez que tuve empleo pude sacar primero a mi esposa. Ella pudo acceder a una visa de trabajo y comenzar a ejercer como médico general. Recuerdo que ella llegó a la media noche al aeropuerto internacional Mariscal Sucre. Casi todas las cintas donde se recoge el equipaje estaban apagadas. Parecía que los guardias de seguridad ya se habían ido a casa. La esperé afuera con una decena de rosas en mano, estaba muy inquieto. El reencuentro y ese primer abrazo fue muy especial para mí, no quería soltarla; es un momento que atesoraré en mi memoria siempre.

Mis hijas llegaron unos meses después, compramos los boletos en alrededor de 600 dólares cada uno. Yo me encontraba trabajando fuera de Quito y mi esposa estaba sola, por eso quise que para el día de la madre se reconfortara con el hecho de que sus hijas lo pasaran con ella.

Nuestro objetivo era ese, estar juntos los cuatro y poder avanzar y estabilizarnos.

Mis hijas llegaron y yo continuaba en mi jornada laboral en el Oriente, no las vi hasta una semana después de su llegada. Y ese día estaba tan feliz y a la vez tan nervioso que sólo puedo recordar el abrazo único, especial, que resumía la nostalgia acumulada.

Ya había pasado ese momento con la llegada de mi esposa, pero la emoción siempre es nueva, porque nadie como los migrantes para entender e identificarse con la palabra reencuentro.

\section{Vivir con entera libertad}

Concluye contándonos que los últimos años de su vida han sido tan vertiginosos y tan difíciles, que está preparado para lo que venga y prefiere no hacer planes a futuro:

50 - Noviembre 2019 - Abril 2020
Hasta este momento mis hijas se sienten realizadas, están estudiando en la Universidad Central del Ecuador y están ya adaptadas al país. Creo que mi destino está junto al de ellas. Si ellas deciden mantenerse aquí, pues aquí me mantendré yo igualmente.

Desde el punto de vista profesional, todavía no he podido ejercer mi especialidad y creo que esa sería mi meta más inmediata, poder ejercer propiamente como ginecólogo. Ahora estoy trabajando como médico general.

Ecuador realmente me gusta. Es un país que nos ha acogido bien, al cual nos hemos adaptado tanto mi esposa, como mis hijas. Creo que el país tiene muchas más cosas positivas que negativas. En cualquier lugar del mundo existirán cosas negativas, y en este caso son perfectibles. El país ofrece oportunidades y tenemos una vida más digna, mucho más estable que la que teníamos en nuestro país y, obviamente, eso siempre hay que agradecer.

Después de cinco años, y haciendo un balance de todo lo sucedido, sólo me queda estar agradecido profundamente con Ecuador, mi nuevo hogar, por las oportunidades que me ha dado, por enseñarme a vivir en entera libertad con la posibilidad hasta de equivocarme. No me arrepiento del paso que di, pero sí desearía que no fuera la fuga la única opción para resolver nuestros problemas.

Creo que sería más efectivo emplear toda nuestra fuerza, nuestro talento e inventiva, para crear en cada uno de nuestros pueblos las condiciones que nos permitan vivir y crecer, pudiendo disfrutar del éxito que tenemos o que podemos alcanzar en ese país sin necesidad de tanto sufrimiento. El tiempo duele y nos hace sabios, tenemos derecho a ser felices 
junto a nuestra familia y nuestros amigos, en la tierra que nos vio nacer y de la que nunca debimos haber partido.

\section{$\star * \star$}

Estas fueron las últimas reflexiones que Félix nos confía. Sus memorias y su presente ahora se forjan en Ecuador, país que, como muchos otros, es la tierra de propios y extraños. País ligado estrechamente con el fenómeno migratorio, pues en apenas 20 años conoció las dos caras de la moneda. Pasó de ser un país emisor de migrantes a ser receptor y convertirse en una tierra de oportunidades para muchos que, como Félix, han llegado al país para emprender una nueva vida.

La historia de Félix permite ir más allá de una voz solitaria y contar a través de su propio testimonio un fenómeno que ha vivido no solamente Ecuador, sino varios países de Latinoamérica y el mundo. Este testimonio trata de contar una historia, de describir, mostrar, explicar y analizar, tan clara y vívidamente como sea posible esta realidad en la que millones de personas alrededor del mundo que deciden abandonar sus raíces para un futuro mejor se encuentran incluidas.

\section{2 \\ El testimonio, una herramienta para conocer al otro}

A partir de esta historia de vida podemos ver cómo el testimonio se perfila como una herramienta para mostrar historias anónimas en la que el otro deja de ser invisible para la academia y los medios de comunicación. También resulta ser anárquico, pues como resalta Hugo
Achugar (2002) es distinto de una versión oficial: "El testimonio contemporáneo parte de los hechos y documentos censurados y termina siendo asimilado por sus lectores solidarios como una historia verdadera que, eventualmente, habrá de adquirir valor mítico" (p. 62).

Y no resulta contrario a lo que Natalia Tobón (2010) indica:

\footnotetext{
El testimonio sí busca retar las formas hegemónicas, pues se concentra en un nuevo sujeto antes olvidado, con una forma libre y menos rígida de presentar la historia, que fusiona métodos del periodismo, la literatura, la sociología y la historia, y, a su vez, le da una especial importancia a la otredad, resalta la alteridad e intenta mostrar la heterogeneidad latinoamericana (p.45).
}

Sin embargo, John Beverley (2002) problematiza el testimonio poniendo en el centro del debate la relación entre el letrado y el subalterno. Coincide en la crítica con Elzbieta Sklodowska (1992) quién indicaba que el testimonio aún es un discurso de élites pues la aceptación y divulgación de esa otra voz dependen exclusivamente de los medios dominantes y letrados. Así, no significa que los otros no digan nada de sus circunstancias, sino que lo que dicen solo se vuelve válido o posee autoridad cultural cuando se amolda a las formas de producción y reproducción de la ciudad letrada que beneficia la palabra escrita.

Aún en sus contradicciones, el testimonio es parte necesaria en el ejercicio de escuchar al otro y, como dice Beverley, es un "arte de la memoria" que mira al pasado y sirve para la construcción histórica de las naciones, que, en muchos casos como el Ecuador, pasa por procesos de cambios atravesados por la migración. 
Por esto es importante utilizar esta herramienta periodística considerando que el testimonio es, en este caso, la narrativa más apropiada, porque pretende dar fe de lo vivido por una persona o grupo de personas.

Precisamente la importancia de este género hace indispensable conocer de qué trata y de dónde proviene. Sobre los orígenes del testimonio existen varias versiones. La narrativa testimonial se incluye en el denominado nuevo periodismo. El nuevo periodismo "tratará de profundizar nuestro entendimiento del mundo, mostrando la realidad desde varios puntos de vista y matices. En otras palabras, la expresión artística será el gancho de este nuevo género" (Sánchez C, 2015, p. 190).

Existe una primera teoría del origen del nuevo periodismo y con él del testimonio, que plantea que inició con Rodolfo Walsh y su obra de no ficción, Operación Masacre, que trata el fusilamiento de un grupo de civiles en un acto por eliminar a los opositores de la dictadura cívico-militar argentina conocida como Revolución Libertadora. Esta obra se realizó gracias a entrevistas y testimonios de los sobrevivientes, sus familiares y autoridades del gobierno. Operación Masacre "se concentra permanentemente sobre los protagonistas, el narrador se ocupa de ellos, de sus pequeñas acciones cotidianas mientras atomiza y fragmenta los episodios fundamentales al seguir a cada personaje en particular" (Amar A, 1990, p. 456). Cabe mencionar que esta es una característica fundamental del testimonio: utilizar fuentes vivas, testimonios de testigos de los hechos para entregar una historia a partir de las voces $\mathrm{y}$ vivencias de los protagonistas de una experiencia profunda que deja una enseñanza a una colectividad.
Natalia Tobón ofrece otra explicación acerca del surgimiento del testimonio. Refuta la afirmación de que este género se inició con la Revolución $\mathrm{Cu}$ bana. Tobón (2010) afirma:

\begin{abstract}
Sin embargo, el testimonio no fue un producto original de América Latina, ni surgió a mediados del siglo XX. Si bien es cierto que fue impulsado en el continente por la Revolución Cubana y luego se desplegó por los demás países, no fue una invención de los intelectuales de la isla. Stéphanie Panichelli remonta la génesis del testimonio hasta las Crónicas de Indias, con Fray Bartolomé de las Casas, y Sklodowska resalta las similitudes de este género con los textos de la época victoriana de Inglaterra, los testimonios sociales soviéticos de los años 30 y la non fiction norteamericana. (p. 49)
\end{abstract}

Como podemos ver, aquí se plantean otras teorías, que el testimonio surgió en la revolución cubana, que fue en las crónicas de India con Bartolomé de las Casas, en la época victoriana de Inglaterra, en la Unión Soviética en los años 30 o con la no ficción norteamericana, en la cual podemos citar a Truman Capote y su novela de no ficción $A$ sangre fría.

Si bien es cierto que existen todas estas versiones, el testimonio, independientemente de dónde provenga, llegó para quedarse y permitirle a los periodistas mostrar y contar al resto la otra verdad, el lado oculto de los sucesos importantes en la sociedad. Por lo tanto, es necesario definir el testimonio, pero aquí surge un problema y es que no existe una definición compartida de lo que es el testimonio por lo cual es importante mencionar lo que dicen varios autores.

Una primera definición plantea que "El testimonio contemporáneo parte de los hechos y documentos censurados y 
termina siendo asimilado por sus lectores solidarios como una historia verdadera que, eventualmente, habrá de adquirir un valor mítico" (Achugar H, 1992, p. 52). El punto central de la conceptualización de Achugar es que el testimonio permite a un testigo dar fe de lo vivido o visto por él y que no forma parte de la historia oficial para relatarlo a los demás.

La Institución Cubana no gubernamental Casa de las Américas incluyó, en 1970, los textos testimoniales en el Premio Casa de las Américas de ese año. Señaló que los testimonios son una práctica muy importante en América Latina porque "documentarán, de fuente directa, un aspecto de la realidad latinoamericana” (García V, 2015, p. 197). Como vemos, el testimonio, desde sus inicios, ha sido el género para contar los problemas sociales y hacer denuncias respecto de estos. Mediante el testimonio se ha podido dejar constancia de las vivencias personales de los marginados por la historia.

En el testimonio, además, se manifiestan dos pactos fundamentales. El primero entre testimoniante y testimonialista, en el cual, según Natalia Tobón (2010):

El primero le cuenta al segundo su historia y espera verla escrita de forma fiel a su historia. El testimonialista le ofrece la idea de tener un frente común y crea un espacio de confianza apropiado para que el testimoniante cuente su historia. (p. 63).

El segundo pacto es entre el escritor y los lectores. Al fin y al cabo, son ellos quienes, mediante la lectura, permiten que el objetivo testimonial se cumpla. El pacto de lectura que el testimonialista hace con el lector es que todo aquello que están leyendo es real. Natalia Tobón (2010) plantea:
Los escritores de testimonios afirman su fidelidad a las declaraciones de los narradores y confiesan de forma esquiva su intervención editorial, su manipulación de las palabras y su reorganización de las historias. Esperan que sus lectores lean sus relatos pensando en que son historias reales, tomándolos como relatos verídicos. (p. 64).

Por lo tanto, el testimonio relata una experiencia individual que refleja el sentimiento colectivo y que se vuelve una herramienta indispensable para descubrir y dar a conocer al otro. Es un nuevo modo de representar los sucesos sociales desde la perspectiva de aquellos que siempre han estado en desventaja y a quiénes no se les ha escuchado. Esto se hace mediante un contenido latente y profundo pero desarrollado de una manera más libre para que el lector pueda conectar y relacionarse con la historia a un nivel personal. Además, se manifiesta más que en cualquier otro género el pacto de confianza entre testimoniante y testimonialista y entre testimonialista y lector.

Partiendo de esta conceptualización se puede pasar entonces a caracterizar el testimonio. En él existe una relación de complicidad entre el testimoniante (protagonista) y el testimonialista (persona que transforma el relato en testimonio escrito, puede ser el periodista). Según Gelpi Juan (2000) en el testimonio existe "el sujeto biográfico (quien escribe y firma el texto) y el sujeto textual (la posición y representación textual) (p. 287). La voz del testimonialista es importante porque ayuda a verbalizar lo que siente y sintió el testimoniante. Habitualmente los intelectuales encargados de transcribir el testimonio ofrecido por el o la informante, lo hacen bajo la forma de la entrevista.

Margaret Randall (2002) coincide con otros críticos en la hibridez del testi- 
monio, pero intenta caracterizarlo al menos en sus aspectos esenciales. Uno de ellos lo denomina "entrega de una historia” en la que hace hincapié en que se debe narrar una historia no de manera general sino mediante hechos o voces particulares.

Por otro lado, Ivonne Jehenson (1990) en su ensayo El testimonio, ¿crónica, autobiografía o género pintoresco? afirma que, en el testimonio, a diferencia de una autobiografía, el yo testimonial habla siempre por un nosotros impersonal que siempre está presente.

En el testimonio, además, el periodista o intelectual debe lograr "meterse dentro de la psicología del personaje y reflejar todos los elementos del ambiente, después de hacer varias entrevistas a pro- fundidad a todos los involucrados". (Peñaranda R, 2012, p. 3). Es importante que se logren describir todos los lugares, emociones y situaciones para que el lector comprenda y se sienta parte de una historia que le dejará una enseñanza, además el lector debe ver que todo aquellos que está leyendo es verdad.

El testimonio, entonces, nos permite, como en este caso, meternos dentro de la psicología del personaje y reflejar todos los elementos del ambiente. Para de esta forma contar al resto, desde las impresiones y visión personal del protagonista, un hecho de características de alto valor noticioso, con todos los detalles que se consideren pertinentes. El periodismo constantemente se nutre de testimonios.

\section{Bibliografía}

Achugar, H. (2002). "Historias paralelas/historias ejemplares: La historia y la voz del otro". En J. Beverley, \& H. Achugar, La voz del otro: testimonio, subalteridad y verdad narrativa (págs. 61-84). Ciudad de Guatemala: Ediciones Papiro S.A.

Amar, A. (1990). La ficción del testimonio. Revista Iberoamericana. Volumen 56. Recuperado de: file:///C:/Users/USER/Downloads/4724-18697-1-PB.pdf

Beverley, J. (2002). "Prólogo a la segunda edición". En J. Beverley, \& H. Achugar, La voz del otro: testimonio, subalteridad y verdad narrativa. Ciudad de Guatemala: Ediciones Papiro S.A.

El País, (8 de octubre de 2018). "Las frases polémicas de BOLSONARO, el candidato ultraderechista a la presidencia de BRASIL". El País. Recuperado de https://www.youtube.com/watch?v=0G_2GpDv4I0

CEPAL (2018). "Pacto Mundial para la Migración otorga un marco de principios comunes no vinculantes para afrontar un tema transfronterizo por naturaleza: Alicia Bárcena. (Comunicado de Prensa)". Recuperado de: https://www.cepal.org/es/comunicados/pacto-mundial-la-migracion-otorga-un-marco-principios-comunes-vinculantes-afrontar-un

EFE, (11 de enero de 2018). "Trump Ilama 'agujeros de mierda' a El Salvador y Haití, según el Washington Post". Recuperado de: https://www.efe.com/efe/america/politica/trump-llama-agujeros-de-mierda-a-el-salvador-y-haitisegun-washington-post/20000035-3489831

INEC. (2019). Registro estadístico de entradas y salidas internacionales 2018. Recuperado de https://www.ecuadorenci- 
fras.gob.ec/documentos/web-inec/Poblacion_y_Demografia/Migracion/2018/Principales_resultados_ESI_ 2018.pdf

Jehenson, I. (1990)." El testimonio, ¿crónica, autobiografía o género picaresco?". Texto Crítico, 75-83.

Miller, S., \& Panayotatos, D. (2019). "A fragile welcome. Refugees International". Recuperado de https://reliefweb.int/sites/reliefweb.int/files/resources/Ecuador\%2BReport\%2B-\%2BJune\%2B2019\%2B-\%2Bfinal.pdf

Organización para la Cooperación y el Desarrollo Económicos. (2013). La migración mundial en cifras. Naciones Unidas, Alto Comisionado. Recuperado de https://www.oecd.org/els/mig/SPANISH.pdf

Peris, B. J. \& Palazón, G. (2015). "El premio Testimonio de Casa de las Américas. Conversación cruzada con Jorge Fornet, Luisa Campuzano y Victoria García". En Avatares del testimonio en América Latina. Kamchatka. Revista de análisis cultural. Recuperado de: file://C:/Users/USER/Downloads/El_premio_Testimonio_de_Casa_de_las_Amer.pdf

Randall, M. (2002). "¿Qué es, y cómo se hace un testimonio?" En J. Beverley, \& H. Achugar , La voz del otro: testimonio, subalteridad y verdad narrativa. Ciudad de Guatemala: Ediciones Papiro S.A.

Redacción Cubadebate, (28 de junio de 2019). "¿Quiénes se benefician del incremento salarial en Cuba?" Cubadebate. Recuperado de: http://www.cubadebate.cu/noticias/2019/06/28/quienes-se-benefician-del-incremento-salarialen-cuba-infografia-y-video/\#.XUh_60hKgps

Sánchez, C. (2015). "El periodismo clásico frente al Nuevo Periodismo. Correspondencias y análisis". Volumen 5. Recuperado de: file://C:/Users/USER/Downloads/Dialnet-ElPeriodismoClasicoFrenteAINuevoPeriodismo-6068743.pdf

Sklodowska, E. (1992). Testimonio hispanoamericano: historia, teoría y poética. New York: Peter Lang Publishing.

Tobón, N. (2010). "La realidad y la ficción del testimonio". En N. Franco, P. Nieto, \& 0. Rincón (Edits.), Tácticas y estrategias para contar [historias de la gente sobre el conflicto y reconciliación en Colombia] (págs. 43-62). Bogotá: Fundación Friedrich Ebert Stiftung.

Vaca, M. E. (5 de febrero de 2017). "En La Florida ya no se escucha a Compay Segundo; muchos cubanos se han ido". El Telégrafo. Recuperado de https://www.eltelegrafo.com.ec/noticias/septimo/1/en-la-florida-ya-no-se-escucha-acompay-segundo-muchos-cubanos-se-han-ido 